\title{
Rivaroxaban versus Warfarin for Prevention of Thromboembolism in Bangladeshi Patients with Non-Valvular Atrial Fibrillation
}

\author{
GOLAM SODRUDDIN ${ }^{1}$, MD. MUKHLESUR RAHMAN ${ }^{1}$, SM AHSAN HABIB ${ }^{1}$, MSI TIPU CHOWDHURY ${ }^{1}$, \\ ADNAN BASHAR ${ }^{1}$, MD. HARISUL HOQUE ${ }^{1}$, ABDUL WADUD CHOWDHURY ${ }^{2}$, NAJNINAKTER ${ }^{3}$, \\ SHAH MD. ZAKIR HOSSAIN, ${ }^{4}$ SAJAL KRISHNA BANERJEE ${ }^{1}$
}

${ }^{1}$ Department of Cardiology, Bangabandhu Sheikh Mujib Medical University (BSMMU), Dhaka, ${ }^{2}$ Department of Cardiology, Dhaka Medical College Hospital, Dhaka. , ${ }^{3}$ Department of Anatomy, Brahmanbaria Medical College, ${ }^{4}$ Department of Nephrology, BSMMU, Dhaka

Address of correspondence: Dr. Golam Sodruddin, Resident, Department of Cardiology, Bangabandhu Sheikh Mujib Medical University, Dhaka. Email: gsshamim1976@gmail.com

\begin{abstract}
Background: The use of Warfarin reduces the rate of ischemic stroke in patients with atrial fibrillation but requires frequent monitoring and dose adjustment. Rivaroxaban, an oral factor Xa inhibitor, may provide more consistent and predictable anticoagulant effects than Warfarin. Methods: In this Open comparison trial, the researchers compared Rivaroxaban (at a daily dose of $20 \mathrm{mg}$ or $15 \mathrm{mg}$ daily in patient with a creatinine clearance of 30-49 $\mathrm{ml} / \mathrm{min}$ ) with dose adjusted Warfarin (target INR 2.0 to3.0) in 2,846 patients with nonvalvular atrial fibrillation and $\mathrm{CH}_{2} D S_{2}-V A S c$ Score 2 or more. The primary efficacy outcome was stroke or systemic embolism and primary safety outcome was major or minor bleeding. This research was designed to determine whether Rivaroxaban have more efficacy and safety than Warfarin for the primary outcomes. Results: Total follow-up period was 6 months. Risk factors and co-morbidities were similar in both groups. Baseline investigations were also similar. Age and sex of both groups were matched. The rate of ischaemic stroke was $1.8 \%$ in Rivaroxaban group, as compared with $2.18 \%$ in the Warfarin group (p 0.479, nonsignificant). The rate of haemorrhagic stroke was $0.53 \%$ in Rivaroxaban group, as compared with $1.36 \%$ in the Warfarin group (p 0.026, significant). Systemic embolism was $0.08 \%$ in Rivaroxaban group, as compared with $0.15 \%$ in the Warfarin group (p 0.561, non-significant). The rate of major bleeding was $0.4 \%$ in Rivaroxaban group and $0.53 \%$ in the Warfarin group (p 0.361, non-significant). The rate of minor bleeding was $2.10 \%$ in Rivaroxaban group, as compared with $2.33 \%$ in the Warfarin group (p 0.681, non-significant). Conclusions: Rivaroxaban have similar efficacy and better safety profile than Warfarin in patients with nonvalvular atrial fibrillation in Bangladeshi population.
\end{abstract}

Key words: Rivaroxaban; Warfarin; Non valvular atrial fibrilation.

University Heart Journal 2020; 16(2): 99-105

Introduction:

Atrial fibrillation (AF) is associated with an increase in the risk of ischemic stroke and accounts for up to $15 \%$ of strokes in persons of all ages and $30 \%$ in persons over the age of 80 years. ${ }^{1}$ The use of vitamin $\mathrm{K}$ antagonists (VKAs) is highly effective for stroke prevention in patients with non-valvular atrial fibrillation and is recommended for persons at increased risk. ${ }^{2-4}$ However, food and drug interactions necessitate frequent coagulation monitoring and dose adjustments, requirement that make it difficult for many patients to use such drugs in clinical practice. ${ }^{5-7}$

Novel oral anticoagulants such as Rivaroxaban are alternatives to VKAs for long-term stroke prevention in patients with non-valvular AF. ${ }^{8-11}$ Newer oral anticoagulants (NOACs) have emerged as an alternative for vitamin $\mathrm{K}$ antagonists (VKAs) for thromboembolic prevention in patients with non-valvular atrial fibrillation. This will have an impact on many practical considerations in the daily management of these patients. Although very promising in many regards (predictable effect without need for monitoring, fewer food and drug interactions, shorter plasma half-life, and an improved efficacy/safety ratio), the proper use of NOACs will require new approaches in many daily aspects. Whereas the 2010 ESC Guidelines (updated 2012) mainly discuss the indications for anticoagulation in general (e.g. based on the $\mathrm{CHA}_{2} \mathrm{DS}_{2}-$ VASc Score) and of NOAC in particular, they guide less on how to use in daily practice. ${ }^{12}$ Moreover, there is no 
study on Rivaroxaban in our country that guide its use in daily practice, safety profile and its efficacy for prevention of thromboembolism.

This research was designed to explore prospectively the efficacy and safety of once-daily Rivaroxaban to prevent stroke and systemic thromboembolism in non-valvular atrial fibrillation in Bangladeshi population in comparison with Warfarin.

\section{Material and Methods:}

Place of study: University Cardiac Center, BSMMU, DHAKA.

Study period: January, 2015 to June, 2016.

Study design: Randomized control trial

Study population: All the patients who were diagnosed as non-valvular atrial fibrillation were collected from the referral advice of 28 (twenty-eight) Consultant Cardiologists of Department of cardiology, BSMMU as well as from inpatient, outpatient and other satellite consultation centers. The patients were selected for anticoagulation at the study place during the study period.

\section{Selection criteria:}

Inclusion criteria

Atrial fibrillation documented by ECG evidence (e.g., 12lead ECG, rhythm strip)

Non-valvular disease documented by Echocardiography, patient with atrial fibrillation who had $\mathrm{CHA}_{2} \mathrm{DS}_{2}-\mathrm{VAS}_{\mathrm{C}}$ Score 2 or more, men or women aged $\geq 18$ years with nonvalvular atrial fibrillation, Female subjects must be postmenopausal, surgically sterile, or, practicing an effective method of birth control before entry and throughout the research.

\section{Exclusion criteria}

Valvular heart disease, Prosthetic heart valve, Planned cardioversion (electrical or pharmacological), Transient atrial fibrillation caused by a reversible disorder (e.g., thyrotoxicosis, recent surgery, MI), Known presence of atrial myxoma or left ventricular thrombus, Infective endocarditis, Active internal bleeding, History of or condition associated with increased bleeding risk including, but not limited to: major surgical procedure or trauma within 30 days before hospitalization, Clinically significant gastrointestinal bleeding within 6 months before hospitalization, history of intracranial, intraocular, spinal, or atraumatic intra-articular bleeding, Chronic hemorrhagic disorder, known intracranial neoplasm, arteriovenous malformation, or aneurysm, planned invasive procedure with potential for uncontrolled bleeding, including major surgery, Platelet count $<90,000 / 1 / 4 \mathrm{~L}$ at the screening visit, sustained uncontrolled hypertension: systolic blood pressure $\geq 180 \mathrm{mmHg}$ or diastolic blood pressure $\geq 100 \mathrm{mmHg}$, severe, disabling stroke within 3 months or any stroke within 14 days before hospitalization, transient ischemic attack within 3 days before hospitalization, indication for anticoagulant therapy for a condition other than atrial fibrillation (e.g., Venous thromboembolism)

Ongoing treatment with: Aspirin $>100 \mathrm{mg}$ daily, aspirin in combination with thienopyridines within 5 days before hospitalization, anticipated need for chronic treatment with a non-steroidal anti-inflammatory drug, systemic treatment with a strong inhibitor of cytochrome P450 3A4, such as ketoconazole or protease, inhibitors, within 4 days before hospitalization, or planned treatment during the time period of the study, treatment with a strong inducer of cytochrome P450 3A4, such as Rifampicin, within 4 days before hospitalization, or planned treatment during the time period of the study, pregnancy or breast-feeding, creatinine clearance $<15 \mathrm{~mL} / \mathrm{min}$, Known significant liver disease (e.g., acute clinical hepatitis, chronic active hepatitis, cirrhosis), or ALT $>3 x$ the ULN, Alcoholics.

Sample size for hypothesis testing of the difference between two proportion. ${ }^{13}$ The estimated sample size was 2,846 patients ( $95 \%$ confidence interval and $80 \%$ power)

Due to genetic, ethnic, body habitus and environmental difference in our population than with European population, the researchers expected higher complications and less thromboembolic protection in Warfarin than that of Rivaroxaban. The researchers expected chance of stroke in Warfarin group $=2.8 \%$ and chance of stroke in Rivaroxaban group $=1.7 \%$ in comparison with European study $($ Warfarin $=2.2 \%$, Rivaroxaban $=1.7 \%) .{ }^{9}$

\section{Patients Selection}

All patients with non-valvular atrial fibrillation, as documented on electrocardiography and moderate-to-high risk for stroke and systemic embolism assessed by $\mathrm{CHA}_{2} \mathrm{DS}_{2}-\mathrm{VAS}_{\mathrm{c}}$ score were enrolled consecutively following the inclusion and exclusion criteria. Then the patients who were selected for anticoagulation were divided into two groups by taking every alternate patient for each group. One group was given Warfarin and another group-Rivaroxaban. Detailed history and examination including evaluation of associated risk factors were done on admission and outpatient consultation. Approval of the research was obtained by the local Ethical Committee. 
All procedures on human subjects were performed in accordance with the latest version of Helsinki Declaration. All subjects who were included in the research signed on informed consent after careful explanation of the research procedures.

\section{Assessment of stroke and thromboembolism}

Risk for stroke and systemic embolism was assessed by $\mathrm{CHA}_{2} \mathrm{DS}_{2}-\mathrm{VAS}_{\mathrm{c}}$ score. $\mathrm{CHA}_{2} \mathrm{DS}_{2}-\mathrm{VAS}_{\mathrm{c}}$ score is an established risk stratification model in patient with nonvalvular atrial fibrillation to predict risk of stroke and systemic thromboembolism . This risk model is defined below as per instruction of AHA guidelines for atrial fibrillation, 2014.

$\mathrm{CHA}_{2} \mathrm{DS}_{2}-\mathrm{VAS}_{\mathrm{C}} \mathrm{SCORE}$

\begin{tabular}{lc}
\hline Parameter & Score \\
\hline Congestive heart failure & 1 \\
Hypertension & 1 \\
Age 75 years or more & 2 \\
Diabetes mellitus & 1 \\
Stroke/TIA/ Thromboembolism & 2 \\
Vascular disease (prior MI, PAD or aortic plaque) & 1 \\
Age 65-74 years & 1 \\
Sex category (e.g. Female sex) & 1 \\
\hline
\end{tabular}

(Craig et al., 2014) $)^{14}$

Patient with $\mathrm{CHA}_{2} \mathrm{DS}_{2}-\mathrm{VAS}_{\mathrm{C}}$ score of two or more were selected for the research.

\section{Treatment procedures}

Rivaroxaban $20 \mathrm{mg}$ daily or $15 \mathrm{mg}$ daily in patient with a creatinine clearance of $30-49 \mathrm{ml} / \mathrm{min}$ was given in one group and dose adjusted Warfarin in another group. Concomitant use of aspirin up to $100 \mathrm{mg}$ daily was permitted. Treatment with thienopyridine antiplatelet agents was prohibited for 5 days before giving Rivaroxaban and throughout the treatment period, except for the patients undergoing cardiovascular interventions.

\section{Follow-up Procedures}

All selected patients were followed up at six months. During visit, surveillance for primary endpoint events, transient ischemic attack, medical compliance, adverse events, and vital status were evaluated. Patients were kept in contact on regular basis by telephone. When problem raised in between schedule follow up, patients advised to contact with the researchers or to visit local registered physicians or hospital. Data were collected over telephone every one month or directed surveillance. The primary efficacy end point were the composite of stroke (ischemic or hemorrhagic) and systemic embolism. Brain imaging was recommended to distinguish hemorrhagic from ischemic stroke. In the presence of atherosclerotic peripheral arterial disease, the diagnosis of embolism was done on angiographic or clinical evidence of abrupt arterial occlusion. The principal safety end point was a composite of major and minor bleeding. Bleeding events involving the central nervous system that met the definition of stroke was adjudicated as hemorrhagic strokes and included in both the primary efficacy and safety end points. A standardized questionnaire and examination was used to screen for stroke symptoms and potential clinical events during follow-up.

\section{Outcome variables}

Primary efficacy end points: Stroke and systemic embolism.

Primary safety end points: Major bleeding and minor bleeding.

\section{Confounding variable:}

Factors that may affect the outcome of research

Compliance to treatment, control of hypertension, control of diabetes mellitus, motivation of the individual socioeconomic status.

To avoid confounding influence close liaison was maintained between all groups of patient. Permanent address, present address including phone number of all patients was kept. Telephone survey was done to assess patient's compliance about treatment. All patients were advised to contact immediately when problem arise. Each patient was advised for follow up at sixth months.

\section{Statistical analysis}

Analysis was conducted on SPSS 16.0 for windows software. Continuous data were expressed as mean \pm SD and categorical data were expressed as frequency and percentage. Test of hypothesis was done by chi-square test ( $\mathrm{x}^{2}$ test). Unpaired student t-test was performed to compare between groups. A P-value of $<0.05$ was considered significant. Multivariate logistic regression analysis was done to see the independent effects of risk factors on primary out come.

\section{Results:}

This open comparison trial was conducted in the University Cardiac Center, Bangabandhu Sheikh Mujib Medical University, Dhaka, over a period of one and half year from January 2015 to June 2016. A total 2846 patients were selected for the research. 
The number of patients who missed follow-up was 90 in Rrivaroxaban group and 95 in Warfarin group. Total followup period was 6 months. Outcome analysis was done between Expected population that was subjects expected during initial evaluation and ultimate observed outcomes that was excluding missing subjects. During follow up in Rivaroxaban group out of 1423 subjects, only 1333 subjects completed their follow up. In Warfarin group out of 1423 subjects only 1328 subjects completed their follow up.

Table I showed age distribution of patients. This research was conducted on patients with age ranging from 18 to 78 years with a mean (SD) age of $57.66 \pm 10.92$ years in Rivaroxaban group and $58.42 \pm 11.62$ years in Warfarin group. There was no significant difference between two groups.

Table II showed gender distribution between two groups. Of them, male-female ratio was 1:1.2 in Rivaroxaban group and 1:1.1 in Warfarin group. Sex differences between two groups were not statistically significant.

Table III showed the coexisting disease of the research subjects, in Rivaroxaban group 70.3\% had hypertension, $54.0 \%$ diabetes, $17.6 \%$ previous stroke or TIA, $7.1 \%$ peripheral vascular disease, $0.28 \%$ congestive heart failure and $0.60 \%$ previous myocardial infarction. In Warfarin group $70.3 \%$ had hypertension, $55.9 \%$ diabetes, $19.5 \%$ previous stroke or TIA, 7.9\% peripheral arterial disease, $0.5 \%$ congestive heart failure and $0.40 \%$ previous myocardial infarction. Differences of coexisting disease between two groups were not statistically significant.

Table IV showed the co-morbidities of the research patients. In Rivaroxaban group, CKD was $0.28 \%$ and liver disease $0.35 \%$. In Warfarin group, CKD was $0.35 \%$ and liver disease $0.63 \%$. There was no significant difference between two groups.

Table V showed the history of previous medications of the study patients, no significant difference between two groups.

Table VI showed the baseline laboratory investigations of both groups. There was no significant difference in baseline investigations findings between groups.

Table-VII showed the expected and observed outcome. Differences between two groups were not statistically significant except haemorrhagic stroke which was more in Warfarin group.

Table VIII provides an overview of the multivariate analysis for the effect of risk factors during follow-up. Logistic regression analysis have shown that history of previous medication (Aspirin \& Warfarin), Hypertension, DM, TIA, PAD and CHF have play a role in changing primary outcome.

Table-I

Age distribution of the study patients $(n=2846)$

\begin{tabular}{|c|c|c|c|c|c|}
\hline \multirow[t]{2}{*}{$\overline{\text { Age }}$} & \multicolumn{2}{|c|}{$\begin{array}{c}\text { Rivaroxaban } \\
(\mathrm{n}=1423)\end{array}$} & \multicolumn{2}{|c|}{$\begin{array}{l}\text { Warfarin } \\
(n=1423)\end{array}$} & \multirow[t]{2}{*}{ P value } \\
\hline & No. & $\%$ & No. & $\%$ & \\
\hline $18-30$ & 2 & 0.1 & 4 & 0.3 & $0.413^{\mathrm{ns}}$ \\
\hline $31-42$ & 101 & 7.1 & 127 & 8.9 & $0.072^{\mathrm{ns}}$ \\
\hline $43-54$ & 167 & 11.7 & 143 & 10.0 & $0.148^{\mathrm{ns}}$ \\
\hline $55-66$ & 453 & 31.8 & 441 & 31.0 & $0.627^{\mathrm{ns}}$ \\
\hline $67-78$ & 700 & 49.2 & 708 & 49.8 & $0.764^{\mathrm{ns}}$ \\
\hline Total & $(1423$ & 100.0 & (1423 & 100.0 & \\
\hline Mean \pm SD & $57.66 \pm 10.92$ & $58.42 \pm 11.62$ & $0.072^{\mathrm{ns}}$ & & \\
\hline
\end{tabular}

Data were presented as frequency, percentage and mean $\pm \mathrm{SD}$. Unpaired t-test was used to compare between two groups.

Table-II

Sex distribution of the study patients $(n=2846)$

\begin{tabular}{|c|c|c|c|c|c|}
\hline \multirow[t]{2}{*}{$\overline{\text { Age }}$} & \multicolumn{2}{|c|}{$\begin{array}{c}\text { Rivaroxaban } \\
(\mathrm{n}=1423)\end{array}$} & \multicolumn{2}{|c|}{$\begin{array}{l}\text { Warfarin } \\
(\mathrm{n}=1423)\end{array}$} & \multirow[t]{2}{*}{ P value } \\
\hline & No. & $\%$ & \begin{tabular}{|l} 
No. \\
\end{tabular} & $\%$ & \\
\hline Male & 752 & 52.8 & 745 & 52.4 & $0.793^{\text {ns }}$ \\
\hline Female & 671 & 47.2 & 678 & 47.6 & \\
\hline$\overline{\text { Total }}$ & (1423 & 100.0 & (1423 & 100.0 & \\
\hline
\end{tabular}

Data were expressed as frequency and percentage. Chi-square test was used to see the association between groups. 


\section{Table-III}

Co-existing disease of the study patients $(n=2846)$

\begin{tabular}{|c|c|c|c|c|c|}
\hline \multirow[t]{2}{*}{$\overline{\text { Coexisting disease }}$} & \multicolumn{2}{|c|}{$\begin{array}{c}\text { Rivaroxaban } \\
(\mathrm{n}=1423)\end{array}$} & \multicolumn{2}{|c|}{$\begin{array}{l}\text { Warfarin } \\
(\mathrm{n}=1423)\end{array}$} & \multirow[t]{2}{*}{ P value } \\
\hline & No. & $\%$ & No. & $\%$ & \\
\hline Hypertension & 1001 & 70.3 & 1000 & 70.3 & $0.967^{\mathrm{ns}}$ \\
\hline Diabetes & 767 & 54.0 & 794 & 55.9 & $0.309^{\text {ns }}$ \\
\hline Previous stroke or TIA & 251 & 17.6 & 278 & 19.5 & $0.193^{\text {ns }}$ \\
\hline Peripheral arterial disease & 101 & 7.1 & 112 & 7.9 & $0.433^{\text {ns }}$ \\
\hline Congestive heart failure & 4 & 0.28 & 7 & 0.50 & $0.365^{\mathrm{ns}}$ \\
\hline Previous myocardial infarction & 8 & 0.60 & 5 & 0.40 & $0.404^{\mathrm{ns}}$ \\
\hline
\end{tabular}

Data were expressed as frequency and percentage. Chi-square test was used to see the association between groups.

Table-IV

Co-morbidities of the study patients ( $n=2846)$

\begin{tabular}{lcccccc}
\hline Co-morbidities & \multicolumn{2}{c}{$\begin{array}{c}\text { Rivaroxaban } \\
(\mathrm{n}=1423)\end{array}$} & & \multicolumn{2}{c}{$\begin{array}{c}\text { Warfarin } \\
(\mathrm{n}=1423)\end{array}$} & P value \\
\cline { 2 - 5 } & No. & $\%$ & & No. & $\%$ & \\
\hline CKD & 4 & 0.28 & 10 & 0.70 & $0.108^{\text {ns }}$ \\
Liver disease & 5 & 0.35 & 9 & 0.63 & $0.284^{\text {ns }}$ \\
\hline
\end{tabular}

Data were expressed as frequency and percentage. Chi-square test was to see the association between groups.

Table-V

History of previous medications of the study patients $(n=2846)$

\begin{tabular}{|c|c|c|c|c|c|}
\hline \multirow[t]{2}{*}{$\begin{array}{l}\text { History of } \\
\text { medication }\end{array}$} & \multicolumn{2}{|c|}{$\begin{array}{c}\text { Rivaroxaban } \\
(\mathrm{n}=1423)\end{array}$} & \multicolumn{2}{|c|}{$\begin{array}{l}\text { Warfarin } \\
(\mathrm{n}=1423)\end{array}$} & \multirow[t]{2}{*}{$P$ value } \\
\hline & $\overline{\text { No. }}$ & $\overline{\%}$ & No. & $\%$ & \\
\hline Aspirin & 286 & 20.8 & 297 & 20.9 & $0.998^{\text {ns }}$ \\
\hline Warfarin & 213 & 15.0 & 212 & 14.9 & \\
\hline Not used & 914 & 64.2 & 914 & 64.2 & \\
\hline Total & (1423 & 100.0 & (1423 & 100.0 & \\
\hline
\end{tabular}

Data were expressed as frequency and percentage. Chi-square test was used to see the association between groups.

Table-VI

Baseline laboratory investigations of the study patients $(n=2846)$

\begin{tabular}{lccc}
\hline Variables & $\begin{array}{c}\text { Rivaroxaban } \\
(\mathrm{n}=1423) \\
\text { Mean } \pm \mathrm{SD}\end{array}$ & $\begin{array}{c}\text { Warfarin } \\
(\mathrm{n}=1423) \\
\text { Mean } \pm \mathrm{SD}\end{array}$ & p value \\
\hline Hemoglobin $(\mathrm{gm} / \mathrm{dl})$ & $11.43 \pm 0.88$ & $11.41 \pm 0.89$ & $0.981^{\mathrm{ns}}$ \\
Serum Creatinine $(\mathrm{mg} / \mathrm{dl})$ & $1.19 \pm 0.13$ & $1.19 \pm 0.14$ & $0.870^{\mathrm{ns}}$ \\
SGPT $(\mathrm{U} / \mathrm{L})$ & $31.57 \pm 5.87$ & $31.64 \pm 5.97$ & $0.761^{\mathrm{ns}}$ \\
Prothombin time $(\mathrm{sec})$. & $6.19 \pm 0.47$ & $6.20 \pm 0.47$ & $0.835^{\mathrm{ns}}$ \\
INR & $1.53 \pm 0.29$ & $1.54 \pm 0.30$ & $0.948^{\mathrm{ns}}$ \\
\hline
\end{tabular}

Data are presented as mean $\pm \mathrm{SD}$. Unpaired t-test was used to compare between two groups. 
Table-VII

Observed and Expected outcome of the patients in two groups

\begin{tabular}{|c|c|c|c|c|c|c|}
\hline \multirow[t]{2}{*}{ Patient group } & \multicolumn{2}{|c|}{ Rivaroxaban } & \multicolumn{2}{|c|}{ Warfarin } & \multicolumn{2}{|c|}{$\mathrm{p}$ value } \\
\hline & $\begin{array}{c}\text { Observed } \\
(\mathrm{n}=1333)\end{array}$ & $\begin{array}{c}\text { Expected } \\
(\mathrm{n}=1423)\end{array}$ & $\begin{array}{c}\text { Observed } \\
(\mathrm{n}=1328)\end{array}$ & $\begin{array}{l}\text { Expected } \\
(\mathrm{n}=1423)\end{array}$ & Observed & Expected \\
\hline No. $(\%)$ & No. $(\%)$ & No. $(\%)$ & No. $(\%)$ & & & \\
\hline Ischemic stroke & $24(1.8 \%)$ & $24(1.7 \%)$ & $29(2.18 \%)$ & $29(2.0 \%)$ & $0.479^{\text {ns }}$ & $0.488^{\mathrm{ns}}$ \\
\hline Hemorrhagic stroke & $7(0.53 \%)$ & $7(0.49 \%)$ & $18(1.36 \%)$ & $18(1.3 \%)$ & $0.026^{\mathrm{s}}$ & $0.027^{\mathrm{s}}$ \\
\hline Systemic embolism & $1(0.08 \%)$ & $1(0.07 \%)$ & $2(0.15 \%)$ & $2(0.14 \%)$ & $0.561^{\mathrm{ns}}$ & $0.563^{\mathrm{ns}}$ \\
\hline Major bleeding & $4(0.30 \%)$ & $4(0.28 \%)$ & $7(0.53 \%)$ & $7(0.49 \%)$ & $0.361^{\mathrm{ns}}$ & $0.365^{\mathrm{ns}}$ \\
\hline Minor bleeding & $28(2.10 \%)$ & $28(1.7 \%)$ & $31(2.33 \%)$ & $31(2.2 \%)$ & $0.682^{\mathrm{ns}}$ & $0.341^{\mathrm{ns}}$ \\
\hline
\end{tabular}

Data were expressed as frequency and percentage. Chi-square test was used to see the association between groups.

Table-VIII

Multivariate analysis of risk factors medication

\begin{tabular}{lcccc}
\hline Variables & P value & OR & \multicolumn{2}{c}{$95 \%$ CI } \\
\cline { 4 - 5 } & & & Lower & Upper \\
\hline HO medication (Aspirin) & .954 & 1.006 & .835 & 1.211 \\
HO medication (Warfarin) & .936 & 1.021 & .842 & 1.225 \\
Hypertension & .269 & 1.114 & .920 & 1.349 \\
DM & .087 & 1.166 & .978 & 1.391 \\
TIA & .067 & 1.207 & .987 & 1.476 \\
PAD & .240 & 1.188 & .892 & 1.583 \\
CHF & .382 & 1.734 & .505 & 5.957 \\
\hline
\end{tabular}

\section{Discussion:}

The main objective of the research was to determine efficacy and safety of Rivaroxaban for prevention of thromboembolism in patients with non-valvular atrial fibrillation in Bangladeshi population. All patients who were diagnosed as a case of non-valvular atrial fibrillation in both inpatient and outpatient department of cardiology, BSMMU and selected for anticoagulation at the study place during the research period. This study was conducted on patients with age ranging from 18 to 78 years with a mean (SD) age of $57.66 \pm 10.92$ years in Rivaroxaban group and $58.42 \pm 11.62$ years in Warfarin group. Breithardt G et al. (2014) have shown similar age distribution. ${ }^{15}$

The male-female ratio studied in this research was $1: 1.2$ in Rivaroxaban group and 1:1.1 in Warfarin group. There were no statistically significant differences between two groups, which is similar to the study findings of Patel et al. (2011). ${ }^{9}$ Common occupations studied in this research were housewife $38.9 \%$ and $39.1 \%$ in Rivaroxaban and Warfarin group respectively. Second common occupation was business $22.1 \%$ in Rivaroxaban group and $22.8 \%$ in Warfarin group. There were no significant differences between the groups.

In this research, Rivaroxaban group had $70.3 \%$ hypertension, $54.0 \%$ diabetes, $17.6 \%$ previous stroke or TIA, $7.1 \%$ peripheral arterial disease, $0.28 \%$ congestive heart failure and $0.60 \%$ previous myocardial infarction. Warfarin group had 70.3\% hypertension, 55.9\% diabetes, $19.5 \%$ previous stroke or TIA, $7.9 \%$ peripheral arterial disease, $0.50 \%$ congestive heart failure and $0.40 \%$ previous myocardial infarction. The associations of coexisting diseases between two groups were not statistically significant. Patel et al. (2011) and Darby et al. (2012) had shown similar results between groups. ${ }^{9,16}$ There was no significant association between two groups in respect of co-morbidities, Breithardt G et al. (2014) had shown similar results in relation to co morbidities between groups. ${ }^{15}$

The differences of outcome findings between two groups were not statistically significant except haemorrhagic stroke. Haemorrhagic stroke is more prevalent in Warfarin 
group than Rivaroxaban group. Patel et al. (2011) had shown in Rocket AF trial that patients of atrial fibrillation getting Warfarin have increased incidence of haemorrhagic stroke than that of Rivaroxaban. ${ }^{9}$

In this research, Multivariate logistic regression analysis have shown that history of previous medication (Aspirin \& Warfarin), hypertension, DM, TIA, PAD and CHF play a role in changing primary outcome. Warfarin is a potent anticoagulant. Its efficacy is still out of question in atrial fibrillation. But major hemorrhage and frequent monitoring of drug efficacy by INR is a potential problem which prevents its use in many patients. Rivaroxaban is an oral anticoagulant which used in atrial fibrillation nowadays for same purposes. Few milestone trial conducted in European population have already shown the efficacy of Rivaroxaban in atrial fibrillation. But untill this research conducted, the researchers did not find any study of Rivaroxaban in atrial fibrillation in our population. This research shown that Rivaroxaban have similar efficacy but less Hemorrhagic stroke in patients with non-atrial fibrillation than that of Warfarin.

\section{Conclusion}

Rivaroxaban have similar efficacy and better safety profile than Warfarin in patients with non-valvular atrial fibrillation in Bangladeshi population.

Limitations of the research

1. Short duration of study

2. Single center study.

\section{Recommendation:}

Rivaroxaban can be safely used in non-valvular atrial fibrilation.

\section{Conflict of interest}

Authors declare that there is no conflict of interest.

\section{Acknowledgements}

This research was a post graduate thesis. The authors would like to thank all the patients who have participated in this randomized controlled trial. Financial support was obtained from the research council of the Bangabandhu Sheikh Mujib Medical University, Dhaka.

\section{References}

1. Wolf PA., Abbott RD., Kannel WB. Atrial fibrillation: a major contributor of stroke in the elderly: the Framingham Study. Arch Intern Med. 1987; 147: 1561-64

2. Hart RG, Benavente O., McBride R., Pearce LA. Antithrombotic therapy to prevent stroke in patients with atrial fibrillation: a meta-analysis. Ann Intern Med. 1999; 131: 492-501.

3. Hart RG, Pearce LA., Aguilar MI. Meta analysis: antithrombotic therapy to prevent stroke in patients who have non-valvular atrial fibrillation. Ann Intern Med. 2007; 146: 857-67.

4. Singer DE, Albers GW, Dalen JE, Go AS, Halperin JL, Manning WJ. Antithrombotic therapy in atrial fibrillation: the Seventh ACCP Conference on Antithrombotic and Thrombolytic Therapy. Chest, 2004; 126: 429S-56S.

5. Albers GW, Yim JM, Belew KM., Bitter N, Hattemer CR, Phillips BG. Status of antithrombotic therapy for patients with atrial fibrillation in university hospitals. Arch Intern Med. 1996; 156: 2311-16.

6. Go AS, Hylek EM., Borowsky LH, Phillips KA, Selby JV, Singer DE. Warfarin use among ambulatory patients with nonvalvular atrial fibrillation: the Anticoagulation and Risk Factors in Atrial Fibrillation (ATRIA) study. Ann Intern Med. 1999; 131:927-34.

7. Piccini JP, Hernandez AF, Zhao X. Quality of care for atrial fibrillation among patients hospitalized for heart failure. $\mathrm{J}$ Am Coll Cardiol. 2009; 54: 1280-97.

8. Connolly SJ, Ezekowitz MD, Yusuf S, Eikelboom J, Oldgren J, Parekh A., Pogue J, Reilly PA.. Dabigatran versus warfarin in patients with atrial fibrillation. N Engl J Med. 2009; 361: 1139-51.

9. Patel MR., Mahaffey KW, Garg J, Pan G, Singer DE, Hacke W. Rivaroxaban versus warfarin in nonvalvular atrial fibrillatiom. N Engl J Med. 2011; 365: 883-91.

10. Granger CB, Alexander JH, McMurray JJ, Lopes RD, Hylek EM, Hanna M. Apixaban versus warfarin in patients with atrial fibrillation. N Engl J Med. 2011; 365: 981-92.

11. Giugliano RP, Ruff CT, Braunwald E, Murphy SA, Wiviott SD, Halperin JL. Edoxaban versus warfarin in patients with atrial fibrillation. N Engl J Med. 2010; 369: 2093-104.

12. Camm AJ, Kirchhof P, Lip GY, Schotten U, Savelieva I., Ernst S. Guidelines for the management of atrial fibrillation: the Task Force for the Management of Atrial Fibrillation of the European Society of Cardiology (ESC). Europac. 2010;12: 1360.

13. Hoque, $\mathrm{M} . \mathrm{ABC}$ of research methodology and biostatistics. $2^{\text {nd }}$ edition. Dhaka: 2014. P-158.

14. Craig TL, Samuel W, Joseph S, Hugh C, Joaquin EC, Joseph CC. AHA/ACC/HRS Guideline for the Management of Patients With Atrial Fibrillation : A Report of the American College of Cardiology/American Heart Association Task Force on Practice Guidelines and the Heart Rhythm Society and in Collaboration With the Society of Thoracic Surgeons. Circulation. 2014; 130: e199-e267.

15. Breithardt G, Baumgartner H., Berkowitz S, Hellkamp A, Jonathan P, Susanna R. Stevens Clinical characteristics and outcomes jtroke Prevention in Patients with Nonvalvular Atrial Fibrillation. American Family Physician. 2014; 85(6): 583-6.

16. Darby A, Dachs R, Garber M. Rivaroxaban vs. Warfarin for Stroke Prevention in Patients with Non-valvular Atrial Fibrillation. American Family Physician. 2012; 85(6): 583-6. 